\title{
Comparing the Use of Dopamine and Norepinephrine in Shock Treatment
}

Majid Jalalyazdi ${ }^{1}$, Amir Reza Parvizian ${ }^{2 *}$ and Shahrzad Mohseny Abyaneh ${ }^{1}$

${ }^{1}$ Mashhad University of Medical Sciences, Mashhad, Iran

${ }^{2}$ Cardiology Department, Islamic Azad University of Mashhad, Mashhad, Iran

\begin{abstract}
Background: The vasopressor agents, such as norepinephrine and dopamine have been endorsed as the standard choice for shock treatment. However, there is controversy regarding the use of vasopressor agents for shock treatment. Considering the use of norepinephrine over dopamine, the present study aimed at assessing the reasons for the reduced death rate among the patients who were in shock.

Methods: Three randomized studies comprising of 62 patients were identified in a meta-analysis that made a comparison of the effects of the two agents on patients suffering from gangrenous shock. Based on the inadequacy of data, a controlled and randomized study was conducted to predict the better results after administration of norepinephrine.

Results: The patients treated with dopamine recorded more arrhythmic occasions than those administered with norepinephrine. The results indicated that norepinephrine is a prudent choice in shock treatment. Norepinephrine was also found to increase in the blood pressure after load, which reduces the cardiac output by increasing the myocardial demand of oxygen.

Conclusion: Even though the death rate did not have a major difference between the patients administered with dopamine and those with norepinephrine, the study raised serious concerns regarding the safety of dopamine therapy. This is because when compared with norepinephrine, dopamine led to more arrhythmias and higher death rate of cardiogenic shock patients.
\end{abstract}

Keywords: Dopamine; Norepinephrine; Shock; Treatment

Abbreviations: SOAP: Sepsis Occurrence in Acutely III Patients

\section{Introduction}

Cardiovascular shock refers to a critical condition that occurs when a patient's heart suddenly fails to pump blood as required by the body. This rare but fatal condition is mostly caused by heart attack and is linked to high death rate $[1,2]$. The fluid administration that forms the firstline of therapeutic strategy does not offer enough stability for the condition of the patient, and the adrenergic agents are regularly needed to correct hypertension [3]. Among the most frequently used agents are dopamine and norepinephrine. Both dopamine and norepinephrine affect the alpha-adrenergic and beta-adrenergic receptors, though to varying degrees. The effects of alpha-adrenergic receptors lead to increased vascular tone. However, it could decrease the cardiac output as well as the regional flow of blood, particularly in cutaneous, renal, and splanchnic beds [4].

On the other hand, beta-adrenergic effects assist in the maintenance of blood flow through inotropic and chronotropic effects as well as increasing splanchnic perfusion. This stimulation from the betaadrenergic effects can bring out the unwanted consequences, including an increase in the cellular metabolism and immunosuppressive effects [5]. Besides, dopamine arouses dopaminergic receptors, which leads to a uniformly bigger rise in renal and splanchnic perfusion, which can expedite lung edema tenacity. Conversely, the stimulation caused by dopamine could lead to negative immunological effects by modifying hypothalamic-pituitary function, leading to a patent drop of prolactin as well as the level of hormones [6].

Hypothetically, norepinephrine and dopamine have varying effects in the splanchnic, kidney and pituitary axis, though the medical consequences of the implied differences are not certain [7]. Experts have recommended that any of the two compounds may be chosen first and applied as a vasopressor in patients suffering from shock. Studies have indicated that more deaths are associated with the use of dopamine than the use of norepinephrine [1]. Therefore, by considering the use of norepinephrine over dopamine, the present study aimed at assessing the ways leading to reduced death rate among the patients who are in shock.

\section{Material and Methods}

\section{Patient's examination}

The study was carried outat various centers in Spain, Belgium, and Austria between April 2003 and September 2007. It included patients over 18 years and above who required a vasopressor agent for treating shock. The following inclusion criteria were taken into consideration: (i) Mean pressure of the patient's artery below $70 \mathrm{~mm} \mathrm{Hg}$; (ii) A systolic pressurebelow $100 \mathrm{~mm} \mathrm{Hg}$ in spite of giving enough fluidsto the patient; and (iii) Hypoperfusion tissue symptoms [8].

The patients who had already been administered with either of the agents, such as norepinephrine, dopamine, epinephrine and phenylephrine, for four hours and above within the current shock episode were excluded [9]. Besides, braindead patients and patients with severe arrhythmia including tachycardia and rapid atrial fibrillation were also excluded from the study. The baseline characteristics of the

*Corresponding author: Amir Reza Parvizian, Cardiology Department, Imam Reza Hospital, Islamic Azad University of Mashhad, Mashhad, Iran, Tel: +98 9153711933 Fax: +98 9153711933; E-mail: parvizian@aftermail.ir

Received August 23, 2016; Accepted October 05, 2016; Published October 10, 2016

Citation: Jalalyazdi M, Parvizian AM, Abyaneh SM (2016) Comparing the Use of Dopamine and Norepinephrine in Shock Treatment. Cardiovasc Pharm Open Access 5: 199. doi: 10.4172/2329-6607.1000199

Copyright: (c) 2016 Jalalyazdi M, et al. This is an open-access article distributed under the terms of the Creative Commons Attribution License, which permits unrestricted use, distribution, and reproduction in any medium, provided the original author and source are credited. 
patients were collected from the records kept in various health centers where the patients had been admitted, with the permission from the doctor on duty.

An irregular heartbeat is known as arrhythmia. Arrhythmia is of three different types. Tachycardia is the condition where the heartbeat's too fast and bradycardia is the condition where the heartbeat's too slow. Fibrillation is the irregular or premature contraction of muscle fibers of the heart. Apart from a stroke that results from improper pumping of the heart, arrhythmia can contribute to heart failure and Alzheimer's disease as well. Norepinephrine is similar to adrenaline. When during certain medical conditions or surgical procedures blood pressure falls drastically, norepinephrine is used to bring blood pressure to normalcy.

\section{Protocol}

The researchers completed randomization using permuted blocks of 6 to 10 that were generated using a computer. These blocks were then stratified depending on the ICU used in the study. A five digit number of reference and assignments for treatment were sealed in opaque envelopes. These envelopes were opened by the person preparing the trialdrug solutions for dopamine and norepinephrine in syringes in accordance with the local ICU's preferences [8].

Every syringe was labeled according to the number that had been assigned randomly. All the healthcare practitioners including the research personnel and the data collectors were not aware of the core tasks. This test sought ethics committee's approval from every center of participation. Besides, written consent was obtained from the patients or their close relatives [10].

The administered dose was determined by the patient's body weight. Dopamine doses were added or reduced by $2 \mu \mathrm{g}$ per kilo in a minute while norepinephrine doses were added by $0.02 \mu \mathrm{g}$ per kilo in a minute. More doses were provided in the cases of emergency. The doctor in charge of every patient determined the target blood pressure [9]. When the sample remained hypotensive even after the administration of the full dose for either of the agents, the researchers added open-labeled norepinephrine. They chose a full dopamine dose of $20 \mu \mathrm{g}$ for each $\mathrm{kg}$ body weight in every minute as the care standard in participating ICUs, in accordance with the recommendations of experts, which was in line with the international guidelines [11].

The agent replacement was done immediately if the patient was in the treatment process using vasopressor at the baseline. If the patient was under the reception of dopamine even after the trial, it could not be terminated and was substituted with norepinephrine fusion with the open label. The use of open-label dopamine was not allowed during the experiment. Vasopressin and epinephrine were administered as saving therapy. In addition, inotropic agents could be administered, if needed, for anincreased cardiac output [12].

While weaning patients from these agents, the norepinephrine in the open-label in the administration process was withdrawn, followed by the withdrawal of the drug solution. In cases of hypotension recurrence, the trialdrug was first resumed then an open-label norepinephrine solution was added when needed [13]

The study was completed in 28 days. The drug used in the study was reinstituted in the case of necessity in the patients discharged from ICU, though they were admitted again within 28 days after randomization. This provided enough room and time for drug exposure. After 28 days, the physician in charge was left with the vasopressor agent choice [14].

If adverse effects were observed in the course of the treatment after using the experimentaldrug, the on-duty physician excluded the patient or the sample from the experiment and set to vasopressor therapy (open label). The other forms of treatment remained with the physicians handling the situation.

\section{Termination points}

The determination of the mortality rate on the $28^{\text {th }}$ day was considered as the endpoint. The secondary endpoints involvedthe death rates during the hospital stay, intensive care unit, at six and twelve months. Others included the period for ICU stay and the total number of days that did not need the sustenance of the organ in which the mean arterial pressure was $65 \mathrm{~mm} \mathrm{Hg}$. Besides, administration of dobutamine as well as the variable hemodynamic deviations or other agents that are inotropicwas also included [15]. The researchers placed adverse events in various categories including arrhythmias. This included ventricular tachycardia, atrial fibrillation or ventricular fibrillation. Other categories included myocardial necrosis, ischemia in appendages or distal limits, skin necrosis and ancillary contaminations [16]

\section{Measured variables}

Data was recorded at intervals of six periods for 48 hours, each $8 \mathrm{~h}$ of the $3^{\text {rd }}, 4^{\text {th }}$ and $5^{\text {th }}$ day as well as once per day on the $6^{\text {th }}, 7^{\text {th }}, 14^{\text {th }}, 21^{\text {st }}$ and $28^{\text {th }}$ day. It included vital signs, cardiac output and hemodynamic variables (which included arterial pressure in systole and diastole, central venous pressure, heart rate as well as pulmonary artery pressure, whenever possible). Similarly, there was a record on the arterial and mixed venous level of blood, cardiac output, vasoactive agent doses and respiratory conditions [17]. Variables on biology, microbiologic data, everyday fluid balance statistics as well as antibiotic therapy were noted every day during the $1^{\text {st }}$ seven days followed by $14^{\text {th }}, 21^{\text {st }}$ and $28^{\text {th }}$ days.

\section{Analyzing statistics}

Observational studies indicated that the use of dopamine is perhaps linked to higher death rates than the use of norepinephrine. Thestudy by Manouchehri et al. [2] on Sepsis occurrence in acutely III patients (SOAP), which involved 1058 shock patients, indicated that the independent use of dopamine posed a risk for death in the ICU. According to the study, the results indicateda death rate of $43 \%$ among dopamine patients and $36 \%$ of norepinephrine patients. It was approximated that having 765 patients in every category, the research would have a supremacy of $80 \%$ to indicate a $15 \%$ relative disparity in the death rate at the $28^{\text {th }}$ day, which is a double-sided alpha leveling at 0.05 .

Given that the degree of the effect resulting from studies under observation is likely to mislead, they chose a sequential trial design that has alternatives on both sides; the trial design demanded the performance of the analyses once the first 50 and 100 patients were included [18]. Then, after including every supplementary 100 patients and terminating the trial in respect to these predetermined limits, dopamine dominance over norepinephrine, norepinephrine superiority over dopamine or lack variance between them was analyzed.

According to the research report, a self-determining statistician along with a physician supervised the effectiveness of the analyses on October 2007. The outcome analysis for the first 1600 patients indicated thatamong the predefined boundaries which had been traversed, the expert advised the stoppage of the trial.

All the statistical analyses were done with regard to the principle of intention-to-treat [19]. An unadjusted chi-square test was employed to analyze the differences in the primary outcome. The results were offered in the form of total and relative dangers and $95 \%$ interims of confidence. The study employed the use of Kaplan-Meier curves (Figure 1) in survival 
approximation in comparison with the log-rank test use [20]. The study used a regression model called Cox proportional-hazards in the evaluation of potentially confusing factors in the results. Selection of the factors was done if the value of $\mathrm{P}$ in univariate analysis was less than 0.20 .

The researchers conducted a predetermined subdivision analysis of the main outcome with regard to the kind of shock that is septic, hypovolemic or cardiogenic. They performed a test for the interface, and its effects are offered in a forest plan (Figure 2).

Analysis of the other double endpoints was done using chisquare tests [21]. The variables that are continuous were compared using unpaired t-test of the student or Wilcoxon rank-sum by using SPSS software. All of the values of $\mathrm{P}$ were found to be binary with no adjustments for multiple tests. As the investigators and statisticians involved in the study did the final analyses, they were ignorant of the treatment assignments of the patients.

\section{Results}

Among the various studies conducted, it can be generalized that the there was a similarity in the baseline characteristics of the

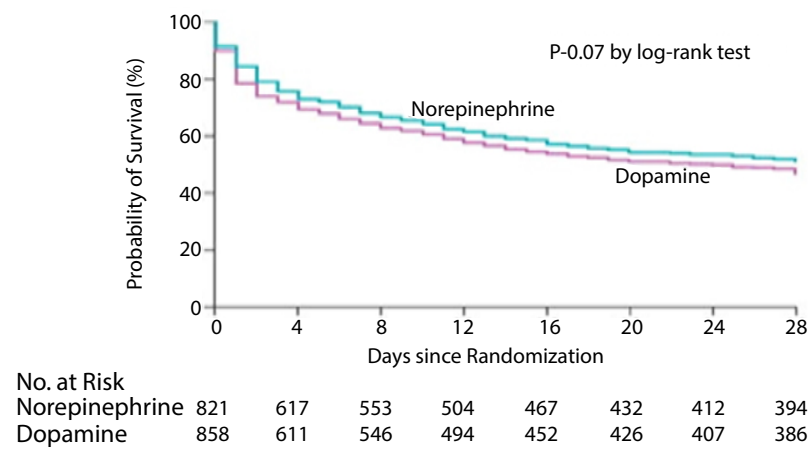

Figure 1: Kaplan-Meier Curves to compare the probability of survival in patients treated with norepinephrine and dopamine indicated that there were no significant variations in the outcome. various groups involved. Averagely, no significant difference was observed using either of the agents [22]. However, the patients treated with dopamine recorded more arrhythmic occasions than those administered with norepinephrine as indicated in various (Figure 3 and Table 1), respectively.

\section{Patients}

An overall number of 1679 patients were involved, of which 858 belonged to the dopamine group and 821 in the norepinephrine group as shown in Figure 3.

A rise in the heart rate was greatly recorded among the patients who were treated with dopamine compared to the norepinephrine patients [23]. However, there was a similarity in cardiac index changes, oxygen saturation and central pressure in the veins as well as the levels of lactation between the groups.

The differences between the two groups were not that significant with regard to most of the characteristics at the baseline [24].

\section{Outcome}

The limit for discontinuing the trial due to inadequate evidence in the disparity between treatments at P-value 0.05 was crossed. There were insignificant differences in death rate between these two groups, especially on the $28^{\text {th }}$ day or the ICU death rates in the hospital at 6 or 12 months as shown in Table 2.

Kaplan-Meier curves used to approximate survival indicated the insignificant differences in the outcomes. The analyses of Cox proportional-hazards (which comprised of the sex, APACHE II score as well as the other pertinent variables) produced similar outcomes [8].

There were more days that did not need trial drug and open-label vasopressors with the norepinephrine group of patients compared to the dopamine group [25]. On the other hand, there were insignificant disparities between the groups that did not need the ICU care and those that did not need organ support [26].

According to De Backer et al. [8], the death rate at $28^{\text {th }}$ day was greater among cardiogenic shock patients who were administered with dopamine than those administered with norepinephrine.

\section{Discussion}

Various findings seem to present a strong challenge for the American College of Cardiology and the American Heart Association that provides guidelines recommending the use of dopamine as the standard agent for treating cardiovascular shock [22]. The results indicated norepinephrine to be a more prudent choice [19]. Initial studies indicated that dopamine increases contractility of myocardial tissues allowing the effect of pharmacological titration, and hence, it has been considered and recommended as the first choice for treating shock $[27,28]$.

Further studies have shown that dopamine is preferred and favored as the first line of medication as it increases the arterial pressure mainly through vasoconstriction having little effect on the cardiac output, stroke volume, and the heart rate [29]. Studies carried out have shown that the use of dopamine increases the stroke volume and heart rate. These characteristics thus make it more capable of causing harmful tachyarrhythmias compared to norepinephrine (Table 3) [30].

Different studies have shown comparisons between Norepinephrine and dopamine in different randomized trials and in a less meta-analysis state and came up with a thesis trial showing the relative risk of death 
Citation: Jalalyazdi M, Parvizian AM, Abyaneh SM (2016) Comparing the Use of Dopamine and Norepinephrine in Shock Treatment. Cardiovasc Pharm Open Access 5: 199. doi: 10.4172/2329-6607.1000199

Page 4 of 7

\begin{tabular}{|c|c|c|}
\hline Variable & $\begin{array}{c}\text { Dopamine } \\
(\mathrm{N}=858)\end{array}$ & $\begin{array}{c}\text { Norepinephrine } \\
\quad(\mathrm{N}=821)\end{array}$ \\
\hline \multicolumn{3}{|l|}{ Age-yr } \\
\hline Median & 68 & 67 \\
\hline Interquartile range & $55-67$ & $56-76$ \\
\hline Male sex-no. (\%) & $507(59.1)$ & $449(54.7)$ \\
\hline \multicolumn{3}{|l|}{ APACHE II Score $†$} \\
\hline Median & 20 & 20 \\
\hline Interquartile range & $15-28$ & $14-27$ \\
\hline \multicolumn{3}{|l|}{ SOFA score $\ddagger$} \\
\hline Median & 9 & 9 \\
\hline Interquartile range & $7-12$ & $6-12$ \\
\hline \multicolumn{3}{|l|}{ Reason for admission-no. (\%) } \\
\hline Medical & $565(65.9)$ & $532(64.8)$ \\
\hline Scheduled surgery & $168(19.6)$ & $161(19.6)$ \\
\hline Emergency surgery & $125(14.6)$ & $128(15.6)$ \\
\hline \multicolumn{3}{|l|}{ Cause of shock-no. (\%) } \\
\hline Sepsis & $542(63.2)$ & $502(61.1)$ \\
\hline Lungs & $278(32.4)$ & $246(30.0)$ \\
\hline Abdomen & $138(16.1)$ & $135(16.4)$ \\
\hline Urine & $51(5.9)$ & $42(5.1)$ \\
\hline Catheter & $14(1.6)$ & $10(1.2)$ \\
\hline Endocardium & $9(1.0)$ & $11(1.3)$ \\
\hline Mediastinum & $10(1.2)$ & $15(1.8)$ \\
\hline Soft tissues & $11(1.3)$ & $13(1.6)$ \\
\hline Other & $15(1.7)$ & $20(2.4)$ \\
\hline \multicolumn{3}{|l|}{ Cardiogenic source } \\
\hline Myocardial infarction & $135(15.7)$ & $145(17.6)$ \\
\hline Dilated cardiomyopathy & $75(8.7)$ & $86(10.5)$ \\
\hline Tamponade & $25(2.9)$ & $19(2.3)$ \\
\hline Pulmonary embolism & $2(0.2)$ & $7(0.9)$ \\
\hline Valvular disease & $10(1.2)$ & $8(1.0)$ \\
\hline After cardiopulmonary bypass & $4(0.5)$ & $5(0.6)$ \\
\hline Other & $19(2.2)$ & $20(2.4)$ \\
\hline Hypovolemia & $138(16.1)$ & $125(15.2)$ \\
\hline Hemorrhage & $130(15.2)$ & $116(14.1)$ \\
\hline Trauma & $17(2.0)$ & $23(2.8)$ \\
\hline Gastrointestinal bleeding & $31(3.6)$ & $22(2.7)$ \\
\hline Bleeding at surgical site & $64(7.5)$ & $57(6.9)$ \\
\hline Other & $18(2.1)$ & $14(1.7)$ \\
\hline Dehydration & $8(0.9)$ & $9(1.1)$ \\
\hline Other & $48(5.9)$ & $44(5.0)$ \\
\hline Spinal & $6(0.7)$ & $8(1.0)$ \\
\hline Peridural § & $13(1.5)$ & $4(0.5)$ \\
\hline Intoxication-related $\boldsymbol{\Upsilon}$ & $7(0.8)$ & $4(0.5)$ \\
\hline Anaphylactic & $3(0.3)$ & $4(0.5)$ \\
\hline Miscellaneous & $13(1.5)$ & $29(3.5)$ \\
\hline \multicolumn{3}{|l|}{ Hemodynamic, respiratory, and biologic variables } \\
\hline Temperature- ${ }^{\circ} \mathrm{C}$ & $36.6 \pm 1.5$ & $36.6 \pm 1.5$ \\
\hline Heart rate-beats/min & $97 \pm 27$ & $95 \pm 25$ \\
\hline Mean arterial pressure-mm $\mathrm{Hg}$ & $58 \pm 13$ & $58 \pm 13$ \\
\hline Mean pulmonary-artery pressure-mm Hg ${ }^{* *}$ & $27 \pm 9$ & $29 \pm 8 \mid$ \\
\hline Pulmonary-artery occlusion Pressure- $\mathrm{mm} \mathrm{Hg}^{* *}$ & $16 \pm 6$ & $18 \pm 6 \mid$ \\
\hline Central venous Pressure-mm $\mathrm{Hg} \dagger \dagger$ & $13 \pm 6$ & $13 \pm 5$ \\
\hline Cardiac index-L/min $/ \mathrm{m}^{2} \ddagger \ddagger$ & $3.11 \pm 1.35$ & $2.77 \pm 1.16$ \\
\hline Arterial pH & $7.32 \pm 0.13$ & $7.32 \pm 0.14$ \\
\hline $\mathrm{PaCO}_{2}-\mathrm{mm} \mathrm{Hg}$ & $42 \pm 16$ & $41 \pm 14$ \\
\hline $\mathrm{PaO}_{2}-\mathrm{mm} \mathrm{Hg}$ & $110 \pm 75$ & $123 \pm 84 \S \S$ \\
\hline
\end{tabular}


Citation: Jalalyazdi M, Parvizian AM, Abyaneh SM (2016) Comparing the Use of Dopamine and Norepinephrine in Shock Treatment. Cardiovasc Pharm Open Access 5: 199. doi: 10.4172/2329-6607.1000199

Page 5 of 7

\begin{tabular}{|c|c|c|}
\hline $\mathrm{SaO}_{2}-\%$ & $95 \pm 5$ & $96 \pm 4 \S \S$ \\
\hline $\mathrm{SvO}_{2}-\%$ Тा & $64 \pm 9$ & $62 \pm 13$ \\
\hline \multicolumn{3}{|l|}{ Lactate-mmol /L } \\
\hline Median & 2.1 & 2.2 \\
\hline Interquartile range & $1.2-4.3$ & $1.2-3.8$ \\
\hline Hemoglobin-g/di & $9.8 \pm 2.5$ & $9.9 \pm 2.5$ \\
\hline \multicolumn{3}{|l|}{ Creatinine-mg/di } \\
\hline Median & 1.4 & 1.3 \\
\hline Interquartile range & $0.8-2.4$ & $0.8-2.3$ \\
\hline Respiratory rate-per min & $21 \pm 8$ & $21 \pm 8$ \\
\hline Ratio of $\mathrm{PaO}_{2}$ to $\mathrm{FiO}_{2}$ & $210 \pm 157$ & $236 \pm 165 \S \S$ \\
\hline \multicolumn{3}{|l|}{ Major therapeutic interventions } \\
\hline Mechanical ventilation-no (\%) & $615(71.7)$ & $580(70.6)$ \\
\hline Tidal volume-ml/kg of ideal body weight & $8.0 \pm 1.9$ & $7.9 \pm 1.9$ \\
\hline Positive end-expiratory pressure-cm of water & $6 \pm 3$ & $6 \pm 2$ \\
\hline $\mathrm{FiO}_{2}$ & $0.59 \pm 0.24$ & $0.58 \pm 0.23$ \\
\hline Renal-replacement therapy-no. (\%) & $63(7.3)$ & $61(7.4)$ \\
\hline \multicolumn{3}{|l|}{ Open-label norepinephrine } \\
\hline Patients treated-no. (\%) & $157(18.3)$ & 107(13.0)§§ \\
\hline Dose- $\mu \mathrm{g} / \mathrm{kg} / \mathrm{min} \mu$ & $0.58 \pm 0.08$ & $0.54 \pm 0.87$ \\
\hline \multicolumn{3}{|l|}{ Epinephrine } \\
\hline Patients treated-no. (\%) & $13(1.5)$ & $9(1.1)$ \\
\hline Dose- $\mu \mathrm{g} / \mathrm{kg} / \mathrm{min}$ & $1.1 \pm 2.8$ & $1.3 \pm 1.9$ \\
\hline \multicolumn{3}{|l|}{ Dobutamine } \\
\hline Patients treated-no. (\%) & $127(14.8)$ & $159(19.4) \mid$ \\
\hline Dose- $-\mu \mathrm{g} / \mathrm{kg} / \mathrm{min}$ & $10 \pm 6$ & $9 \pm 6$ \\
\hline \multicolumn{3}{|l|}{ Vasopressin } \\
\hline Patients treated-no. (\%) & $2(0.2)$ & $2(0.2)$ \\
\hline Dose-U/min & 0.03 & 0.03 \\
\hline Corticosteroids-no. (\%) II & $101(11.8)$ & $76(9.3)$ \\
\hline
\end{tabular}

\pm Plus-minus values are means $\pm \mathrm{SD}$. To convert the values for creatinine to micromoles per liter, multiply by $88.4, \mathrm{FiO}_{2}$ denotes fraction of inspired oygen, $\mathrm{PaCO}{ }_{2}$ partial pressure of arterial cardon dioide, $\mathrm{PaO}_{2}$ partial pressure of arterial oxygen, $\mathrm{SaO}_{2}$ arterial oxygen saturation, and $\mathrm{SvO}_{2}$ venous oygen saturation.

† Scores on the Acute Physiologic and Chronic Health Evaluation II (APACHE II) scale range from 0 to 71 , with higher values indicating more severe disease.

$\ddagger$ Score on the Sequential Organ Failure Assessment (SOFA) scale range from 0 to 4 for each organ system, with higher score indicating more severe organ dysfunction.

$\S$ Peridural shock refers to vasodilatory shock induced by peridural or epidural infusion in otherwise uncomplicated procedures.

I The 11 cases of intoiation were drug overdoses ( 5 cases) and voluntary intoiaction with benzodiazepines (3), trycyclic antidepressants (2), and calcium-channel blockers (1).

$\mid \mathrm{P}<0.05$ for the comparison of norepinephrine with dopamine.

** Data were available for 277 patients.

t† Data were available for 1249 patients.

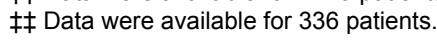

$\S \S \mathrm{P}<0.01$ for the comparison of norepinephrine with dopamine.

IT Data were available for 357 patients.

II Corticosteriods administered at baseline included hydrocortisone and prednisolone.

Table 1: Baseline characteristics.

\begin{tabular}{|c|c|c|c|c|}
\hline Time Period & Dopamine & Norepinephrine & $\begin{array}{l}\text { Odds ratio } \\
(95 \% \mathrm{Cl}) \dagger\end{array}$ & $P$ value \\
\hline & \multicolumn{2}{|c|}{ Percent Mortality } & & \\
\hline During stay in intensive care unit & 50.2 & 45.9 & $1.19(0.98-1.44)$ & 0.07 \\
\hline During hospital stay & 59.4 & 56.6 & $1.12(0.92-1.37)$ & 0.24 \\
\hline At 28 days & 52.5 & 48.5 & $1.17(0.97-1.42)$ & 0.10 \\
\hline At 6 mo & 63.8 & 62.9 & $1.06(0.86-1.31)$ & 0.71 \\
\hline At $12 \mathrm{mo}$ & 65.9 & 63.0 & $1.15(0.91-1.46)$ & 0.34 \\
\hline
\end{tabular}

* Data were available for 1656 patients in the intensive care unit, in the hospital, and at 28 days; for 1443 patients at 6 months; and for 1036 patients at 12 months. $\dagger$ Odds ratios for death are for the comparison of the dopamine group with the norepinephrine group.

Table 2: Mortality rates.

when using norepinephrine as compared to the use of dopamine [31]. On the other hand, norepinephrine leads to an increase in the blood pressure as well as after load. The increase is likely to reduce the cardiac output by increasing the myocardial demand of oxygen. However, various studies lean towards the use of norepinephrine as a better option in shock treatment [32].
Treatment of shock is dependent on various factors. There are various types of trauma other than septic shock, which is caused by bacteria. Anaphylactic shock results from an allergic reaction or hypersensitivity to an antigen. During its treatment epinephrine is used. Cardiac shock is a result of damage to the heart, while fluid or blood loss leads to hypovolemic shock. Medicines such as dopamine, 
Citation: Jalalyazdi M, Parvizian AM, Abyaneh SM (2016) Comparing the Use of Dopamine and Norepinephrine in Shock Treatment. Cardiovasc Pharm Open Access 5: 199. doi: 10.4172/2329-6607.1000199

Page 6 of 7

\begin{tabular}{|c|c|c|c|}
\hline Variable & $\begin{array}{l}\text { Dopamine } \\
(\mathrm{N}-858)\end{array}$ & $\begin{array}{c}\text { Norepinephrine } \\
\text { (Ni821) }\end{array}$ & P Value \\
\hline \multicolumn{4}{|l|}{ Support free days through day 28} \\
\hline \multicolumn{4}{|l|}{ Vasopressors not needed } \\
\hline Trial drug & $11.0 \pm 12.1$ & $12.5 \pm 12.1$ & 0.01 \\
\hline Open label vassopressors & $12.6 \pm 12.5$ & $14.2 \pm 12.3$ & 0.007 \\
\hline Mechanical ventilation not needed & $8.5 \pm 11.2$ & $9.5 \pm 11.4$ & 0.13 \\
\hline Renal support not needed & $12.8 \pm 12.4$ & $14.0 \pm 12.3$ & 0.07 \\
\hline Intensive care not needed & $8.1 \pm 10.3$ & $8.5 \pm 10.3$ & 0.43 \\
\hline \multicolumn{4}{|l|}{ Length of stay-no. of days } \\
\hline Intensive care unit & & & 0.12 \\
\hline Median & 5 & 5 & \\
\hline Interquartile range & $1-11$ & $2-12$ & \\
\hline Hospital & & & 0.22 \\
\hline Median & 11 & 12 & \\
\hline Interquartile range & $2-28$ & $3-28$ & \\
\hline Cause of death in hospital-no & & & 0.31 \\
\hline Refractory shock & $196 / 426(46)$ & $155 / 381(41)$ & \\
\hline Withdrawal or withholding of therapy & $193 / 426(45)$ & $190 / 381(50)$ & \\
\hline Brain death or severe postanoic lesions & $37 / 426(9)$ & $36 / 381(9)$ & \\
\hline \multicolumn{4}{|l|}{ Adverse events } \\
\hline Arrhythmias-no. (\%) & $207(24.1)$ & $102(12.4)$ & $<0.001$ \\
\hline April fibrillation & $176(20.5)$ & $90(11.0)$ & \\
\hline Ventricular tachycardia & $21(2.4)$ & $8(1.0)$ & \\
\hline Ventricular stimulation & $10(1.2)$ & $4(0.5)$ & \\
\hline Myocardial infarction-no. (\%) & $19(2.2)$ & $25(3.0)$ & 0.29 \\
\hline \multicolumn{4}{|l|}{ New infectious episode } \\
\hline No of episodes & & & 0.69 \\
\hline Median & 1 & 1 & \\
\hline Interquartile range & $0-1$ & $0-1$ & \\
\hline Patience with at least one episode & $674(78.6)$ & $619(75.4)$ & 0.35 \\
\hline Skin ischemia-no. (\%) & $56(6.5)$ & $34(4.1)$ & 0.09 \\
\hline Mild\% & $46(5.4)$ & $28(3.4)$ & \\
\hline Severe\% & $10(1.2)$ & $6(0.7)$ & \\
\hline Arterial occlusion-no. (\%) $\int$ & $23(2.7)$ & $20(2.4)$ & 0.12 \\
\hline Areas of figures & $5(0.6)$ & $1(0.1)$ & \\
\hline Legs & $7(0.8)$ & $13(1.6)$ & \\
\hline Bowel & $11(1.3)$ & $6(0.7)$ & \\
\hline
\end{tabular}

\pm Plus-minus values are means $\pm \mathrm{SD}$

$\dagger$ Mild skin ischemia was defined as a cold and cyanotic skin area, with capillary refill time of more than 2 seconds.

$\ddagger$ Severe skin ischemia was defined as a cold and black skin, with no bleeding on puncture.

§ Arterial occlusion in an extremity was considered to be present if an extremity was cold, if the capillary refill time was prolonged ( $>2 \mathrm{~s}$ ), and if there was no pulse in the nutritive artery. Vascular occlusion in the bowel was considered to be present if bowel ischemia was detected by laparotomy, computed tomography, or colonoscopy.

Table 3: Secondary outcomes and effects.

dobutamine, epinephrine, and norepinephrine are used in the treatment of hypovolemic shock. Severity of shock and its cause is determined by conducting tests on the patient. In normal circumstances, IV fluids are offered besides medications that increase blood pressure.

\section{Conclusion}

Observational studies carried out on a smaller scale suggested that dopamine treatment may be detrimental to septic shock patients. On 
Citation: Jalalyazdi M, Parvizian AM, Abyaneh SM (2016) Comparing the Use of Dopamine and Norepinephrine in Shock Treatment. Cardiovasc Pharm Open Access 5: 199. doi: 10.4172/2329-6607.1000199

Page 7 of 7

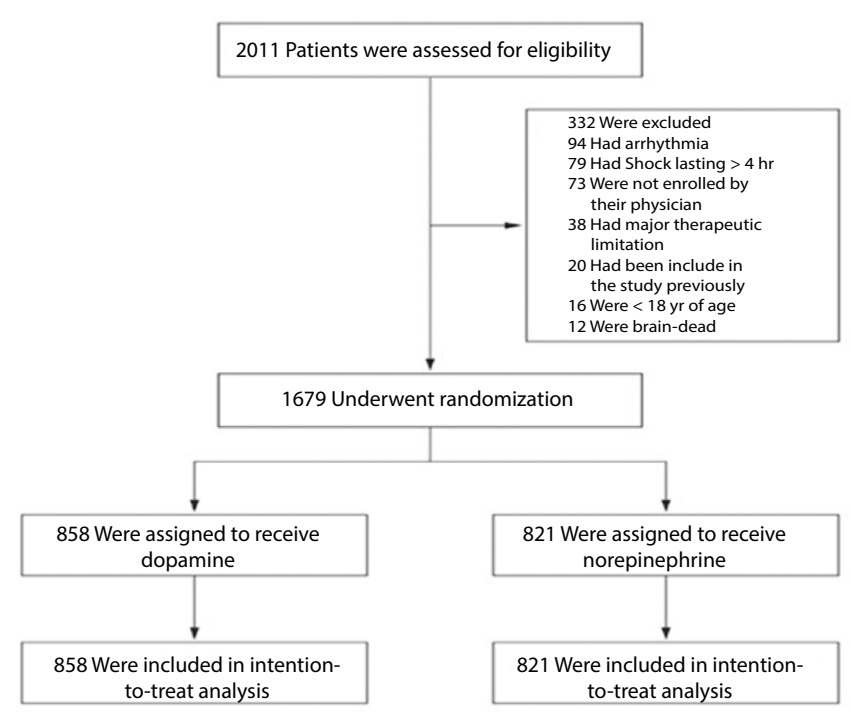

Figure 3: Screening and enrolment. The study enrolled a sum of 1679 patients. Out of them, 821 were in the norepinephrine team while 858 were in the dopamine team. Every patient was followed to the $28^{\text {th }}$ day. Information on the outcome of staying in the health facility was available for $98.6 \%$ of the patients (i.e., 1656 patients). Information on the six months issue had $85.9 \%$ of the patients (i.e., 1443 patients) as well as data during the 12-month results for 1036 patients, which represented $61.7 \%$.

the contrary, other reports showed higher death rate among the patients who used norepinephrine as compared to dopamine. Even though the death rate did not have a major difference between the patients administered with dopamine and those with norepinephrine, the study raised serious concerns regarding the safety of dopamine therapy. This is because when compared with norepinephrine, dopamine led to more arrhythmias and higher death rate of cardiogenic shock patients.

\section{References}

1. Thongprayoon C, Cheungpasitporn W, Harrison A, Carrera P, Srivali N, et al (2016) Temporal trends in the utilization of vasopressors in intensive care units: an epidemiologic study. BMC Pharmacol Toxicol 17: 19.

2. Manouchehri N, Bigam D, Churchill T, Rayner D, Joynt C, et al. (2013) A comparison of combination dopamine and epinephrine treatment with highdose dopamine alone in asphyxiated newborn piglets after resuscitation. Pediatr Res 73: 435-442.

3. Dellinger R, Levy M, Rhodes A, Annane D, Gerlach H, et al. (2013) Surviving Sepsis Campaign: International Guidelines for Management of Severe Sepsis and Septic Shock, 2012. Intensive Care Med 39: 165-228.

4. Finfer S, Vincent J, Vincent J, De Backer D (2013) Circulatory Shock. N Engl J Med 369: 1726-1734.

5. Aletti F, Conti C, Ferrario M, Ribas V, Bollen Pinto B, et al. (2016) ShockOmics: amultiscale approach to the identification of molecular biomarkers in acute heart failure induced by shock. Scand J Trauma Resusc Emerg Med 24: 9.

6. Thiele H, Ohman E, Desch S, Eitel I, de Waha S (2015) Management of cardiogenic shock. Eur Heart J 36: 1223-1230.

7. Mitrić G, Udy A, Bandeshe, H, Clement P, Boots R (2016) Variable use of amiodarone is associated with a greater risk of recurrence of atrial fibrillation in the critically ill. Crit Care 20: 90.

8. De Backer D, Aldecoa C, Njimi H, Vincent J (2012) Dopamine versus norepinephrine in the treatment of septic shock. Crit Care Med 40: 725-730.

9. Nativi-Nicolau J, Selzman CH, Fang JC, Stehlik J (2014) Pharmacologic therapies for anacute cardiogenic shock. Curr Opin Cardiol 29: 250-257.

10. Herrick AL, Murray AK, Ruck A, Rouru J, Moore TL, et al. (2014) A doubleblind, randomized, placebo-controlled crossover trial of the $2 \mathrm{C}$-adrenoceptor antagonist ORM-12741 for prevention of cold-induced vasospasm in patients with systemic sclerosis. Rheumatology 53: 948-952.
11. Maas J, Pinsky M, de Wilde R, de Jonge E, Jansen J (2013) Cardiac Output Response to Norepinephrine in Postoperative Cardiac Surgery Patients. Crit Care Med 41: 143-150.

12. Asfar P, Meziani F, Hamel J, Grelon F, Megarbane B, et al. (2014) High versus Low Blood-Pressure Target in Patients with Septic Shock. N Engl J Med 370: 1583-1593.

13. Green JP, Adams J, Panacek EA, Albertson TA (2013) The 2012 Surviving Sepsis Campaign: Management of Severe Sepsis and Septic Shock-An Update on the Guidelines for Initial Therapy. Curr Emerg Hosp Med Rep 1: 154-171.

14. Rock KC, Bakowitz M, McCunn M (2013) Advances in the Management of the Critically Injured Patient in the Operating Room. Anesthesiol Clin 31: 67-83.

15. Radosevich J, Patanwala A, Erstad B (2016) Hepatotoxicity in Obese Versus Nonobese Patients With Acetaminophen Poisoning Who Are Treated With Intravenous N-Acetylcysteine. Am J Ther 23: e714- e719.

16. van der Voort PH, van Zanten M, Bosman RJ, van Stijn I, Wester JP, et al. (2015) Testing a conceptual model on the early opening of the microcirculation in severe sepsis and septic shock. Eur J Anaesthesiol 32: 189-198.

17. Sivayoham N, Rhodes A, Jaiganesh T, van Zyl Smit N, Elkhodhair S, et al (2012) Outcomes from implementing early goal-directed therapy for severe sepsis and septic shock. Eur J Emerg Med 19: 235-240.

18. Van Zanten A (2014) Guideline bundles adherence and mortality in severe sepsis and septic shock: Results of a National Patient Safety Program in the Netherlands. BMJ Qual Saf 23: 346.

19. Polito A, Parisini E, Ricci Z, Picardo S, Annane D (2012) Vasopressin and terlipressin in adult vasodilatory shock. Crit Care 16: 470.

20. Ranieri VM, Thompson BT, Barie PS, Dhainaut JF, Douglas IS, et al. (2012) Drotrecogin Alfa (Activated) in Adults with Septic Shock. N Engl J Med 366: 2055-2064.

21. Lian J, Huang X, Pai N, Deng C (2015) Chronic betahistine co-treatment reverses olanzapine's effects on dopamine D2 but not 5-HT2A/2C bindings in rat brains. Prog Neuropsychopharmacol Biol Psychiatry 56:75-80.

22. Zhao JY, Sun JW, Gu ZY, Wang J, Wang EL, et al. (2012) Genetic Polymorphisms of the TYMS Gene Are Not Associated with Congenital Cardiac Septal Defects in a Han Chinese Population. PLoS One 7: e31644.

23. Gordon AC, Mason AJ, Perkins GD, Stotz M, Terblanche M, et al. (2014) The Interaction of Vasopressin and Corticosteroids in Septic Shock. Crit Care Med 42: 1325-1333.

24. Seymour CW, Rosengart MR (2015) Septic Shock. JAMA 314: 708

25. Radosevich JJ, Patanwala AE, Erstad BL (2015) Norepinephrine Dosing in Patients With Septic Shock. Am J Crit Care 25: 27-32.

26. Verma D, Khuroo T, Talegaonkar S, Iqbal Z (2015) Nanopotentiated combination cancer therapy: Chemotherapeutic and chemosensitizer (2C approach). Med Hypotheses 84: 580-582.

27. Ventura AM, Shieh HH, Bousso A, Góes PF, de Cássia FO, et al. (2015) Double-Blind Prospective Randomized Controlled Trial of Dopamine Versus Epinephrine as First-Line Vasoactive Drugs in Pediatric Septic Shock. Crit Care Med 43: 2292-2302.

28. (2015) Palmer-2C-Läsionen: Arthroskopisches Debridement und sekundäre Ulnaverkürzung. Handchir Scan 4: 201-202.

29. Cheng J, Kozikowski AP (2015) We Need $2 \mathrm{C}$ but Not 2B: Developing Serotonin 2C (5-HT 2C) Receptor Agonists for the Treatment of CNS Disorders. Chem Med Chem 10: 1963-1967.

30. Fernández J, Gustot T (2012) Management of bacterial infections in cirrhosis J Hepatol 56: S1-S12.

31. D'Aragon F, Belley-Cote EP, Meade MO, Lauzier F, Adhikari NK, et al. (2015) Blood Pressure Targets For Vasopressor Therapy. Shock 43: 530-539.

32. Eckert J, Johnson A (1987) Workshop 2C: Advances in diagnosis. Int J Parasitol 17: 1017-1018. 